\title{
Manual mid-stromal dissection as a low risk procedure to stabilize mild to moderate progressive keratoconus
}

Rénuka S Birbal ${ }^{1,2,3}$, Korine van Dijk ${ }^{1,2}$, Jack S Parker ${ }^{1,5}$, Henny Otten ${ }^{6}$, Maha Belmoukadim ${ }^{1,2,3}$, Lisanne Ham ${ }^{1,2,3}$, Lamis Baydoun ${ }^{1,2}$, Isabel Dapena ${ }^{1,2}$ and Gerrit R J Melles ${ }^{1,2,3,4^{*}}$ (D)

\begin{abstract}
Background: To evaluate the efficacy of manual mid-stromal dissection in stabilizing progressive keratoconus. Methods: Surgeries were performed in 16 eyes of 14 patients with progressive keratoconus. All eyes were examined before and at 1 day, 1 week, 1, 3, 6 and 12 months after surgery, and every 6 months thereafter. Pentacam (simK, Kmax and pachymetry), best corrected visual acuity (BCVA) and subjective refraction were recorded up to the latest follow-up visit (mean follow-up time $6.6 \pm 2.4$ years).

Results: All surgeries were uneventful, and no postoperative complications occurred. Keratometry values $(n=15)$ stabilized in 6/11 eyes (55\%) with a preoperative Kmax $<60.0$ diopter (D), while all eyes $>60$ D showed continued progression. In 11/15 eyes (73\%) pachymetry was unchanged. BCVA with spectacles remained stable in 7/12 eyes (58\%) and improved $\geq 2$ Snellen lines in 5/12 eyes (42\%). BCVA with a contact lens remained stable in 4/9 eyes (44\%), improved $\geq 2$ Snellen lines in 3/9 eyes (33\%) and deteriorated in 2/9 eyes (22\%).

Conclusions: Manual mid-stromal dissection was effective in $50 \%$ of keratoconic corneas with Kmax values $<60 \mathrm{D}$ and may be considered in cases ineligible for other interventions such as UV-crosslinking, stromal ring implantation or Bowman layer transplantation. An advantage of the procedure may be that the tissue is unaltered and that no synthetic or biological implant is required.
\end{abstract}

Keywords: Keratoconus, Manual cornea dissection, Progressive ectasia, Surgical technique

\section{Background}

Until a decade ago, keratoconus (KC) has been treated with contact lens fitting until disease progression required penetrating keratoplasty (PK) or deep anterior lamellar keratoplasty (DALK) [1]. In 2003, Wollensak et al. introduced ultraviolet-A-induced collagen crosslinking (UV-CXL) as a concept to stabilize corneal ectasia by strengthening the stromal collagenous corneal matrix [2]. Its use may be limited to keratoconic corneas that measure at least $400 \mu \mathrm{m}$ in thickness [2]. Alternatively, intrastromal corneal ring segments (ICRS) have been described to modify the corneal contour [1]. All these procedures share the disadvantage of significantly altering the corneal anatomy which may bear the risk of potential complications in the long term $[3,4]$.

To offer patients a low risk alternative to halt or slow down disease progression, we introduced a different approach: 'manual mid-stromal dissection'. We hypothesized that stabilization of corneal ectasia in eyes with keratoconus may be obtained through a wound healing effect within the stroma following manual dissection.

The aim of this study was to evaluate the efficacy of the procedure in stabilizing keratoconic corneas as well as to substantiate a significantly lower incidence of complications.

\footnotetext{
* Correspondence: research@niios.com; http://www.niios.com

${ }^{1}$ Netherlands Institute for Innovative Ocular Surgery (NIIOS) Rotterdam, Laan op Zuid 88, 3071AA Rotterdam, The Netherlands

${ }^{2}$ Melles Cornea Clinic Rotterdam, Rotterdam, The Netherlands

Full list of author information is available at the end of the article
}

\section{Methods}

\section{Patient data}

A total of 16 eyes of 14 patients ( 6 female), with a mean age of $33.8 \pm 12.1$ years (range, 19-72 years), underwent 
manual mid-stromal dissection (Table 1) and had a mean follow-up of $6.6 \pm 2.4$ years (range, 1.6-9.4 years). All treated eyes had documented evidence of keratoconus progression in the year prior to surgery (defined as $\geq 1.0 \mathrm{Di}-$ opters (D) change in maximum keratometry [Kmax] values (measured by Scheimpflug-based corneal tomography [5])) with or without a history of subjective decline in visual acuity and were included in this analysis. Eyes with concomitant ocular disease not related to keratoconus and eyes with previous episodes of hydrops were excluded from treatment. All patients signed an institutional review board-approved informed consent form prior to surgery. The study was conducted according to the tenets of the Declaration of Helsinki [6].

\section{Surgical technique}

Manual mid-stromal dissection was derived from a technique previously described by Melles et al. to create a lamellar dissection plane in deep anterior lamellar

Table 1 Demographics and preoperative baseline characteristics

\begin{tabular}{|c|c|c|c|c|}
\hline Case no. & $\begin{array}{l}\text { Age (years)/ } \\
\text { Gender }\end{array}$ & Eye & $\begin{array}{l}\text { Keratoconus } \\
\text { grade }^{c}\end{array}$ & Remarks \\
\hline 1 & $38 / F$ & $\mathrm{OD}$ & $|-| \mid$ & \\
\hline $2^{\mathrm{a}}$ & $31 / M$ & OS & III-IV & \\
\hline $3^{\mathrm{a}}$ & $31 / M$ & OD & III-IV & \\
\hline 4 & $27 / M$ & $\mathrm{OD}$ & $\|$ & \\
\hline 5 & $36 / F$ & OS & IV & $\begin{array}{l}\text { Chronic allergic } \\
\text { conjunctivitis }\end{array}$ \\
\hline $6^{\mathrm{b}}$ & $23 / \mathrm{M}$ & OD & III & \\
\hline 7 & $72 / F$ & OS & $\|-|\||$ & $\begin{array}{l}\text { Preexisting central } \\
\text { corneal scarring, } \\
\text { Diabetes mellitus } \\
\text { type II }\end{array}$ \\
\hline 8 & $34 / \mathrm{M}$ & OS & III-IV & \\
\hline 9 & $34 / \mathrm{M}$ & OS & I & \\
\hline 10 & $34 / \mathrm{M}$ & OS & $\|-\mid\|$ & $\begin{array}{l}\text { Preexisting central } \\
\text { corneal scarring }\end{array}$ \\
\hline 11 & $45 / M$ & $\mathrm{OD}$ & $\|-|\||$ & \\
\hline 12 & $26 / F$ & OS & $|-| \mid$ & \\
\hline $13^{b}$ & $24 / \mathrm{M}$ & OS & $\|-\| \|$ & \\
\hline 14 & $28 / F$ & OS & IV & $\begin{array}{l}\text { Chronic allergic } \\
\text { conjunctivitis }\end{array}$ \\
\hline 15 & $37 / F$ & OD & III-IV & $\begin{array}{l}\text { Preexisting central } \\
\text { corneal scarring }\end{array}$ \\
\hline 16 & $19 / \mathrm{M}$ & $\mathrm{OD}$ & III & \\
\hline Average & 33.8 & & & \\
\hline SD & 12.1 & & & \\
\hline
\end{tabular}

$F=$ female; $M=$ male; $O D=$ right; $O S=$ left

a,b Note that two patients (cases no. 2, 3, 6, and 13) underwent bilateral manual crosslinking

'Keratoconus grading according to Pentacam Topographic Keratoconus classification [10] keratoplasty (DALK) [7]. For stabilization of keratoconic corneas, a manual mid-stromal dissection plane was created at approximately $50-70 \%$ corneal depth (to avoid perforation in the anterior chamber) instead of the 90 95\% depth of dissection commonly used in DALK (Fig. 1).

Surgery was performed under local anesthesia (retrobulbar, $4 \mathrm{~mL} 1 \%$ ropivacaine hydrochloride with $1 \mathrm{~mL}$ 150 IU Hyason) with the patient positioned in anti-Trendelenburg position and a Honan's balloon applied for $10 \mathrm{~min}$. A side port was created at either the 3- or 9-o'clock limbus to completely fill the anterior chamber with air. Then, a 5-mm frown-shaped scleral incision was created at 12 o'clock, $1-2 \mathrm{~mm}$ from the limbus and tunneled into the superior cornea. Subsequently, guided by the air-endothelium interface, manual lamellar dissection was performed with a dissection spatula (Melles spatula set; DORC International BV, Zuidland, The Netherlands) at $50-75 \%$ stromal depth creating a circumferential mid-stromal pocket from limbus to limbus. Finally, the air was removed from the anterior chamber and the eye was pressurized with a balanced salt solution.

Postoperative topical treatment included chloramphenicol $0.5 \%$ for 2 weeks; ketorolac tromethamine $0.4 \%$ and dexamethasone $0.1 \%$ for 4 weeks; switched to fluorometholone $0.1 \%$ at 1 month postoperatively, which was subsequently tapered and stopped over months.

\section{Data collection}

All eyes were examined at standardized time-intervals before and after surgery: 1 day, 1 week, 1, 3, 6 and 12 months and every 6 months thereafter. Data regarding the first two postoperative years and the latest follow-up visit were included in this analysis. Slit-lamp biomicroscopy, Scheimpflug-based corneal tomography (Pentacam HR; Oculus, Wetzlar, Germany) and endothelial cell density (ECD) measurements were recorded and best-spectacle corrected visual acuity (BSCVA) and best-contact lens corrected visual acuity (BCLVA) were measured.

Regarding Scheimpflug-based corneal tomography, only images of sufficient quality were used for evaluation. BCVA was measured using a Snellen letter chart. The endothelium was photographed and evaluated in vivo using a Topcon SP3000p non-contact autofocus specular microscope (Topcon Medical Europe BV, Capelle a/d IJssel, The Netherlands). Images of the central corneal window were analyzed and manually corrected; up to three measurements of endothelial cell density were averaged (if the central endothelium could not be visualized, paracentral images were used for analysis).

\section{Statistical analysis}

All analyses were performed using Excel Software for Windows. Progression of Kmax was defined as an increase in $\mathrm{Kmax}$ of $\geq 1.0 \mathrm{D}$ throughout the follow-up 


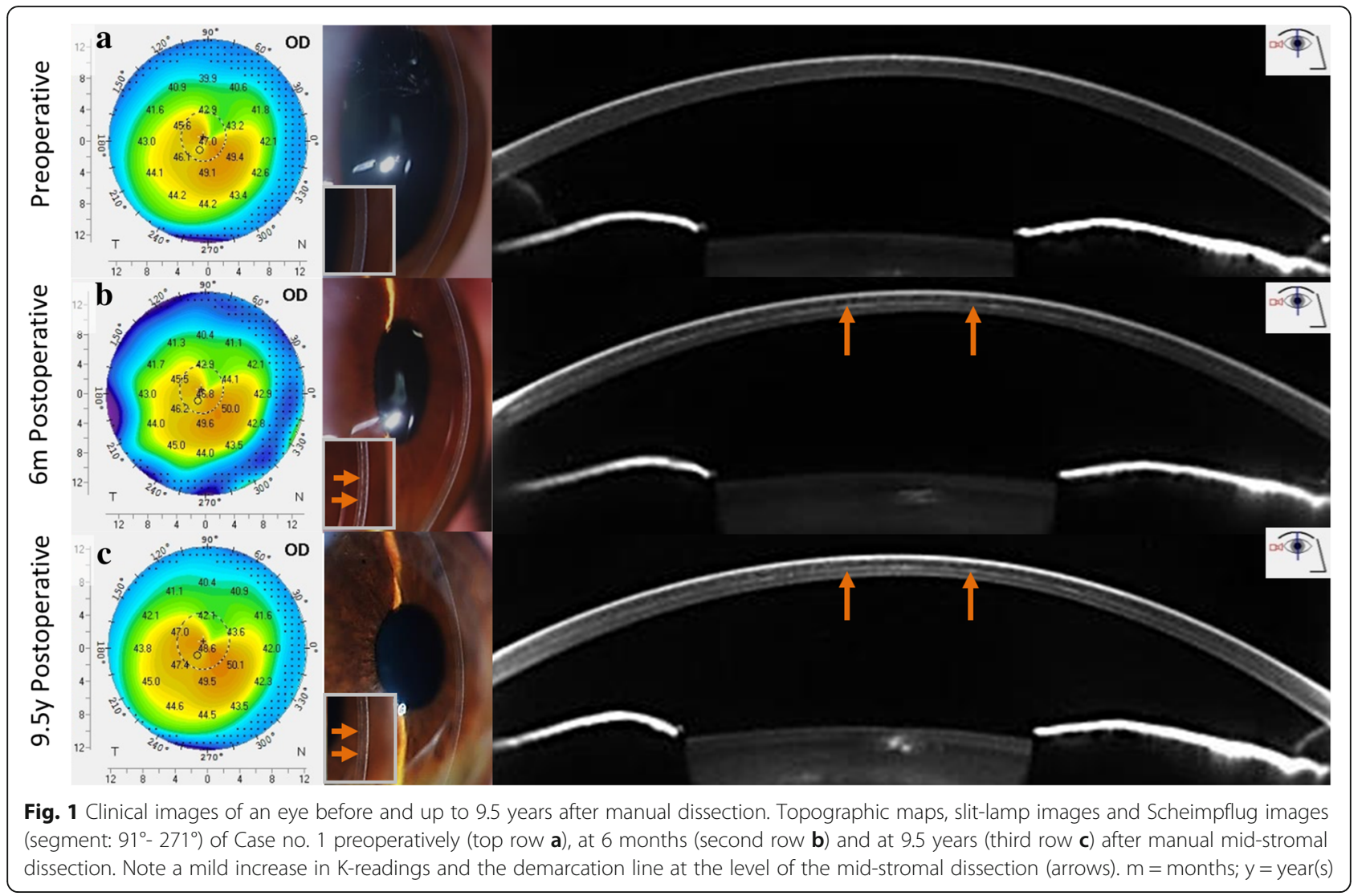

period. Changes in thinnest point thickness (TPT) of less than 5\% were considered stable. BCVA was defined as stable for changes $\leq 1$ Snellen lines, and as improving or deteriorating for changes $\geq 2$ Snellen lines. Independent paired Student's t-test was performed to assess significant differences between preoperative and consecutive postoperative follow-up measurements. Statistical analysis could not be adjusted for inclusion of fellow eyes due to the small cohort size. Additional statistical analysis, excluding fellow eyes, however, yielded equal results. A $P$-value below an alpha of 0.05 was considered to be statistically significant. Reported data were expressed as mean \pm standard deviation (SD) for continuous variables or percentages.

\section{Results}

All surgical procedures were uneventful. After surgery, the mid-stromal dissection could be visualized in all treated corneas as a thin white scar by biomicroscopy (Fig. 1).

Case no. 7 was excluded from Pentacam analysis due to a preoperative measurement of insufficient quality. During the $6.6 \pm 2.4$ year follow-up period, $6 / 15$ eyes $(40 \%)$ showed no changes in keratometry values (simK and/ or Kmax) (Cases no. 2, 3, 4, 8, 11 and 12), while an increase of $\geq 1.0 \mathrm{D}$ was observed in $9 / 15$ eyes $(60 \%)$ (Cases no. 1, 5, 6, 9, 10, 13, 14, 15 and 16) (Table 2). In eyes with a preoperative $K \max <60.0 \mathrm{D}$, postoperative Kmax showed no differences compared to preoperative values in 6/11 eyes (55\%), whereas an increase in Kmax $>1.0 \mathrm{D}$ was observed in $4 / 4$ eyes $(100 \%)$ with a preoperative Kmax >60.0 D. The fellow eyes of patients of whom both eyes were included were observed to behave in the same way (Cases no. 2 and 3 were both stable and cases no. 6 and 13 were both progressive). Cases no. 5 and 14 both had a preoperative Kmax of $>70.0 \mathrm{D}$ and needed a subsequent Bowman layer transplantation to manage continued keratoconus progression at 47 and 19 months of follow-up, respectively, after which they were excluded from further analysis. Patient age did not correlate with disease progression $(P \geq .05$; Table 1$)$.

No changes in central corneal thickness (CCT) or TPT were observed in $11 / 15$ eyes (73\%), whereas a decrease in TPT of more than $5 \%$ was observed in $4 / 15$ eyes (27\%) (Cases no. 9, 10, 11 and 14) (Table 3). Three of these four cases (Cases no. 9, 10 and 14) also showed an increase in keratometry values.

Pre- and postoperative BSCVA measurements were available for $12 / 16$ eyes $(75 \%)$ and remained unchanged in $7 / 12$ eyes (58\%) and improved $\geq 2$ Snellen lines in $5 /$ 
Table 2 Pre- and postoperative corneal curvature

\begin{tabular}{|c|c|c|c|c|c|c|c|c|c|c|c|c|}
\hline \multirow{2}{*}{$\begin{array}{l}\text { Case } \\
\text { no. }\end{array}$} & \multirow{2}{*}{$\begin{array}{l}\text { Max FU } \\
\text { years (m) }\end{array}$} & \multicolumn{4}{|c|}{ SimK-value (D) } & \multirow{2}{*}{$\begin{array}{l}\Delta \text { Pre-op to } \\
\text { latest FU (D) }\end{array}$} & \multicolumn{4}{|c|}{ Kmax (D) } & \multirow{2}{*}{$\begin{array}{l}\Delta \text { Pre-op to } \\
\text { latest FU (D) }\end{array}$} & \multirow[t]{2}{*}{ Remarks } \\
\hline & & Pre-op & $1 \mathrm{yr} . \mathrm{FU}$ & 2 yr. FU & $\overline{\text { Latest FU }}$ & & Pre-op & 1 yr. FU & 2 yr. FU & $\overline{\text { Latest FU }}$ & & \\
\hline 1 & $9.4(113)$ & 46.2 & 46.6 & 46.4 & 47.2 & 1.0 & 51.4 & 47.1 & 51.1 & 52.8 & $1.4^{c}$ & \\
\hline $2^{\mathrm{a}}$ & $3.1(37)$ & 44.8 & 44.5 & 45.1 & 44.5 & -0.3 & 59.9 & 60.5 & 60.1 & 59.8 & -0.1 & \\
\hline $3^{\mathrm{a}}$ & $3.0(36)$ & 43.5 & 44.5 & 43.2 & 43.3 & -0.2 & 58.6 & 59.4 & 58.1 & 58.4 & -0.2 & \\
\hline 4 & $9.2(110)$ & 45.8 & 45.6 & n.a. & 45.8 & 0 & 49.9 & 48.2 & n.a. & 50.3 & 0.4 & \\
\hline 5 & $3.9(47)$ & 53.4 & 54.0 & 55.3 & 56.2 & 2.8 & 71.8 & 71.1 & 73.5 & 74.5 & $2.7^{c}$ & $\begin{array}{l}\text { Bowman Layer } \\
\text { Transplantation } \\
(47 \mathrm{~m})\end{array}$ \\
\hline $6^{\mathrm{b}}$ & 8.7 (104) & 49.0 & 49.0 & 49.1 & 48.9 & -0.1 & 56.5 & 57.1 & 57.8 & 58.5 & $2.0^{c}$ & \\
\hline 7 & $8.8(106)$ & n.a. & (52.2) & (52.2) & (52.4) & & n.a. & (58.4) & (57.8) & (58.7) & & \\
\hline 8 & $7.3(87)$ & 50.1 & 49.5 & 50.2 & 51.3 & 1.2 & 58.6 & 57.2 & 57.1 & 57.6 & -1.0 & \\
\hline 9 & $6.8(82)$ & 37.1 & 38.0 & 38.0 & 38.6 & 1.5 & 46.4 & 46.5 & 46 & 52.0 & $5.6^{c}$ & \\
\hline 10 & $8.5(102)$ & 52.0 & 50.9 & 52.8 & 57.5 & 5.5 & 58.7 & 60.1 & 62.9 & 70.7 & $12.0^{c}$ & \\
\hline 11 & $7.3(87)$ & 42.5 & 42.4 & 42.6 & 42.3 & -0.2 & 53.4 & 52.8 & 53.7 & 52.8 & -0.6 & \\
\hline 12 & $8.1(97)$ & 47.6 & 46.9 & n.a. & 47.2 & -0.4 & 49.4 & 48.3 & n.a. & 47.9 & -1.1 & \\
\hline $13^{b}$ & 7.7 (92) & 48.3 & 48.1 & 47.8 & 49.2 & 0.9 & 55.5 & 55.9 & 54.6 & 59.9 & $4.4^{c}$ & \\
\hline 14 & $1.6(19)$ & 61.9 & 60.1 & n.a. & n.a. & -1.8 & 72.5 & 76.8 & n.a. & n.a. & $4.3^{c}$ & $\begin{array}{l}\text { Bowman Layer } \\
\text { Transplantation } \\
(19 \mathrm{~m})\end{array}$ \\
\hline 15 & $6.9(83)$ & 58.2 & 57.9 & 60.0 & 61.5 & 3.3 & 69.2 & 70.9 & 78.1 & 74.3 & $5.1^{c}$ & \\
\hline 16 & $5.8(70)$ & 51.1 & 50.8 & 51.2 & 52.2 & 1.1 & 60.3 & 59.9 & 60.1 & 62.3 & $2.0^{c}$ & \\
\hline Average & $6.6(79.5)$ & 48.8 & 48.6 & 48.5 & 49.7 & +1.0 & 58.1 & 58.1 & 59.4 & 60.6 & 2.5 & \\
\hline SD & $2.4(29.4)$ & 6.2 & 5.7 & 6.0 & 6.7 & 1.8 & 7.9 & 9.2 & 8.9 & 9.4 & 3.5 & \\
\hline$P$-value $(p$ & re-op to Fl & & 0.357 & 0.060 & & & & 0.970 & 0.223 & & & \\
\hline
\end{tabular}

FU = follow-up; $M a x=$ maximum; $D=$ diopter; Pre-op = preoperative; $y r .=$ year; $m=$ months; $\Delta=$ difference; simK = simulated keratometry; $K m a x=$ maximum keratometry value; $S D=$ standard deviation; n.a. = not available

a,b Note that two patients (cases no. 2, 3, 6, and 13) underwent bilateral manual crosslinking

'Progression of corneal ectasia after mid-stromal manual dissection

Case no. 7 was excluded from keratometry analysis due to a preoperative measurement of insufficient quality

12 eyes (42\%). Pre- and postoperative BCLVA measurements were available for $9 / 16$ eyes (60\%). Scleral lenses were applied in $5 / 9$ eyes (56\%), rigid gas permeable contact lenses in $2 / 9$ eyes (22\%), a soft contact lens in $1 / 9$ eyes $(11 \%)$ and one eye (11\%) switched from a scleral lens to a soft contact lens. BCLVA remained stable in $4 /$ 9 eyes (44\%), improved $\geq 2$ Snellen lines in 3/9 eyes (33\%) and deteriorated in $2 / 9$ eyes (22\%). The two eyes with a deterioration in BCLVA showed continued keratoconus progression and underwent subsequent Bowman layer transplantation (Cases no. 5 and 14). Mean spherical equivalent did not change from preoperatively to the latest postoperative follow-up visit $(-2.3 \pm 3.8 \mathrm{D}$ preoperative to $-2.4 \pm 4.1 \mathrm{D}$ postoperative, $P \geq .05$ ). The mean refractive cylinder changed from $-3.7 \pm 2.4 \mathrm{D}$ to $-4.6 \pm 1.2 \mathrm{D}(P \geq .05)$ (Table 4$)$.

Endothelial cell density averaged $2670 \pm 290$ cells $/ \mathrm{mm}^{2}$ preoperatively $(n=12)$ and remained stable up to the latest follow-up visit $(P \geq .05)$. No postoperative complications were observed throughout the study period.

\section{Discussion}

In the past two decades, several surgical treatment options have been introduced aiming to delay or halt disease progression in keratoconic eyes and attempting to postpone or avoid PK or DALK [1]. UV-CXL has been shown to effectively delay progression of corneal ectasia, whereas implantation of ICRS may result in a corneal flattening, thereby improving the uncorrected visual acuity and allowing prolonged contact lens tolerance [8-13]. More recently, Bowman layer transplantation - implantation of an isolated Bowman layer into a manually dissected mid-stromal pocket - was introduced as a treatment option for corneas with advanced keratoconus (Kmax >70 D and/or pachymetry $<400 \mu \mathrm{m})$ that are no longer eligible for UV-CXL or ICRS [14, 15].

The surgeries performed for this study originate from the time period preceding the technique for Bowman layer transplantation and UV-CXL approval in most countries [16, 17]. Our study suggests that it may be 
Table 3 Pre- and postoperative pachymetry values

\begin{tabular}{|c|c|c|c|c|c|c|c|c|c|c|c|c|}
\hline \multirow[t]{2}{*}{ Case no. } & \multirow{2}{*}{$\begin{array}{l}\text { Max FU } \\
\text { years (m) }\end{array}$} & \multicolumn{4}{|c|}{ Central corneal thickness $(\mu \mathrm{m})$} & \multirow{2}{*}{$\begin{array}{l}\Delta \text { Pre-op to } \\
\text { latest FU (\%) }\end{array}$} & \multicolumn{4}{|c|}{ Thinnest point thickness $(\mu \mathrm{m})$} & \multirow{2}{*}{$\begin{array}{l}\Delta \text { Pre-op to } \\
\text { latest FU (\%) }\end{array}$} & \multirow[t]{2}{*}{ Remarks } \\
\hline & & Pre-op & 1 yr. FU & 2 yr. FU & Latest FU & & Pre-op & $1 \mathrm{yr} . \mathrm{FU}$ & $2 \mathrm{yr} . \mathrm{FU}$ & Latest FU & & \\
\hline 1 & $9.4(113)$ & 505 & 502 & 509 & 490 & -3.0 & 492 & 487 & 496 & 478 & -2.8 & \\
\hline $2^{a}$ & $3.1(37)$ & 513 & 510 & 508 & 509 & -0.8 & 483 & 487 & 472 & 492 & +1.9 & \\
\hline $3^{\mathrm{a}}$ & $3.0(36)$ & 534 & 520 & 530 & 524 & -1.9 & 504 & 487 & 482 & 493 & -2.2 & \\
\hline 4 & $9.2(110)$ & 466 & 469 & n.a. & 473 & +1.5 & 451 & 449 & n.a. & 444 & -1.6 & \\
\hline 5 & $3.9(47)$ & 414 & 410 & 406 & 404 & -2.4 & 336 & 321 & 328 & 329 & -2.1 & $\begin{array}{l}\text { Bowman Layer } \\
\text { Transplantation } \\
(47 \mathrm{~m})\end{array}$ \\
\hline $6^{b}$ & 8.7 (104) & 470 & 475 & 473 & 458 & -2.6 & 446 & 458 & 453 & 441 & -1.1 & \\
\hline 7 & $8.8(106)$ & n.a. & (414) & (419) & (423) & & n.a. & (407) & (408) & (429) & & \\
\hline 8 & $7.3(87)$ & 568 & 571 & 564 & 557 & -1.9 & 511 & 497 & 502 & 506 & -1.0 & \\
\hline 9 & $6.8(82)$ & 470 & 456 & 488 & 476 & +1.3 & 419 & 344 & 395 & 379 & -9.5 & \\
\hline 10 & $8.5(102)$ & 339 & 350 & 325 & 329 & -2.9 & 313 & 292 & 287 & 274 & -12.5 & \\
\hline 11 & $7.3(87)$ & 497 & 486 & 479 & 486 & -2.2 & 481 & 465 & 456 & 451 & -6.2 & \\
\hline 12 & $8.1(97)$ & 471 & 481 & n.a. & 477 & +1.3 & 466 & 480 & n.a. & 471 & +1.1 & \\
\hline $13^{b}$ & $7.7(92)$ & 469 & 467 & 469 & 457 & -2.6 & 434 & 438 & 442 & 440 & +1.4 & \\
\hline 14 & $1.6(19)$ & 459 & 385 & п.а. & 385 & -16.1 & 366 & 305 & n.a. & 305 & -16.7 & $\begin{array}{l}\text { Bowman Layer } \\
\text { Transplantation } \\
\text { (19 m) }\end{array}$ \\
\hline 15 & $6.9(83)$ & 392 & 376 & 377 & 369 & -5.9 & 338 & 332 & 325 & 322 & -4.7 & \\
\hline 16 & $5.8(70)$ & 475 & 453 & 458 & 453 & -4.6 & 465 & 440 & 453 & 445 & -4.3 & \\
\hline Average & $6.6(79.5)$ & 469 & 461 & 466 & 456 & & 434 & 419 & 424 & 418 & & \\
\hline SD & $2.4(29.4)$ & 56 & 59 & 67 & 61 & & 65 & 76 & 73 & 76 & & \\
\hline \multicolumn{3}{|c|}{$P$-value (pre-op to FU) } & 0.121 & 0.126 & & & & 0.035 & 0.010 & & & \\
\hline
\end{tabular}

FU = follow-up; Pre-op = preoperative; $m=$ months; $y r .=$ year; $\mu m=$ micrometer; $n . a .=$ not available; $S D=$ standard deviation

${ }^{a, b}$ Note that two patients (cases no. 2, 3, 6, and 13) underwent bilateral manual crosslinking

Case no. 7 was excluded from pachymetry analysis due to a preoperative measurement of insufficient quality

effective in halting corneal ectasia progression in about $50 \%$ of cases with a preoperative $\mathrm{Kmax}<60.0 \mathrm{D}$.

Eyes ineligible for UV-CXL or ICRS due to corneal steepness and/or thickness, ocular surface disease related to atopic constitution - varying from epitheliopathy, chronic allergic conjunctivitis, cobblestone eyelids, limbal unrest - or corneal scars, may benefit from manual mid-stromal dissection as the procedure does not affect the ocular surface and does not involve a graft or synthetic implant. A further advantage of manual mid-stromal dissection may be that, apart from a thin layer of scar tissue induced, the cornea is unaltered, leaving room for all other future treatment options.

In the ophthalmic literature, the success rate of various procedures is less often stratified for different patient groups. For example, fair-skinned and blue-eyed Caucasian patients may show higher risk of epithelial wound healing problems and/or conjunctival reactibility, which comes into play with virtually all treatment options involving the ocular surface, and which determines the outcomes and incidence of postoperative complications in different geographic regions. For that reason, the choice of procedure may also depend on risk profiles for a given patient population [18].

On the other hand, our study showed that mid-stromal dissection alone fails to achieve stabilization of corneal ectasia in eyes with advanced ectasia (Kmax > 60.0 $\mathrm{D}$ preoperatively). For this group of eyes that was not responsive, a Bowman layer transplantation may be considered, a procedure that offers the same benefits in avoiding postoperative complications, but that does require a donor Bowman layer implant. In a recent study, $90 \%$ of eyes with progressive keratoconus and a preoperative Kmax $\geq 67.5$ D, showed stabilization after Bowman layer transplantation [14, 19].

All the eyes included in this study, also the eyes of over 30 and even 40 years of age had documented evidence of keratoconus progression in the year preceding manual mid-stromal dissection. Progression of keratoconus beyond the age of 30 years was also confirmed in a recent study by Gokul et al. [20]. While the absence of a control group is a limitation of this study, it would be questionable and unethical to include eyes with documented progression of keratoconus without treating 
Table 4 Pre- and postoperative visual acuity and astigmatism

\begin{tabular}{|c|c|c|c|c|c|c|c|c|c|}
\hline \multirow{2}{*}{$\begin{array}{l}\text { Case } \\
\text { no. }\end{array}$} & \multirow{2}{*}{$\begin{array}{l}\text { Max FU } \\
\text { in years }(\mathrm{m})\end{array}$} & \multicolumn{2}{|c|}{ BSCVA Snellen (Decimal) } & \multicolumn{2}{|c|}{ BCLVA Snellen (Decimal) } & \multirow{2}{*}{$\begin{array}{l}\text { Cylinder in D } \\
\text { Pre-op }\end{array}$} & \multirow{2}{*}{$\begin{array}{l}\text { SE in D } \\
\text { Latest FU }\end{array}$} & \multirow{2}{*}{$\begin{array}{l}\text { Cylinder in D } \\
\text { Pre-op }\end{array}$} & \multirow{2}{*}{$\begin{array}{l}\text { SE in D } \\
\text { Latest FU }\end{array}$} \\
\hline & & Pre-op & Latest FU & Pre-op & Latest FU & & & & \\
\hline 1 & $9.4(113)$ & $20 / 60(0.3)$ & $20 / 40(0.5)$ & n.a. & $20 / 40(0.5)$ & -5.50 & -2.50 & -6.00 & -4.25 \\
\hline 2 & $3.1(37)$ & $20 / 20(1.0)$ & $20 / 16(1.2)$ & п.а. & n.a. & -5.00 & 2.50 & -5.50 & 2.50 \\
\hline 3 & $3.0(36)$ & $20 / 20(1.0)$ & $20 / 16(1.2)$ & n.a. & n.a. & -5.00 & 2.50 & -5.50 & 2.75 \\
\hline 4 & $9.2(110)$ & $20 / 25(0.8)$ & $20 / 25(0.8)$ & $20 / 25(0.8)$ & n.a. & -3.25 & -7.13 & -6.50 & -7.50 \\
\hline 5 & $3.9(47)$ & $20 / 50(0.4)$ & n.a. & $20 / 22(0.9)$ & $20 / 50(0.4)$ & 0.00 & 0.00 & n.a. & n.a. \\
\hline 6 & $8.7(104)$ & 20/33 (0.6) & $20 / 20(1.0)$ & n.a. & $20 / 16(1.2)$ & -4.00 & -0.50 & -4.00 & -1.25 \\
\hline 7 & $8.8(106)$ & $20 / 25(0.8)$ & $20 / 25(0.8)$ & n.a. & n.a. & -4.00 & -2.00 & -3.50 & -1.50 \\
\hline 8 & $7.3(87)$ & $20 / 50(0.4)$ & $20 / 28(0.7)$ & 20/33 (0.6) & $20 / 25(0.8)$ & -6.00 & -7.00 & -5.00 & -2.00 \\
\hline 9 & $6.8(82)$ & $20 / 28(0.7)$ & $20 / 20(1.0)$ & 20/25 (0.8) & 20/20 (1.0) & -1.00 & -5.75 & -2.75 & -8.50 \\
\hline 10 & $8.5(102)$ & n.a. & $20 / 80(0.25)$ & $20 / 28(0.7)$ & $20 / 50(0.4)$ & n.a. & n.a. & 0.00 & -4.00 \\
\hline 11 & $7.3(87)$ & n.a. & $20 / 28(0.7)$ & n.a. & $20 / 20(1.0)$ & -7.50 & 0.50 & -6.00 & 0.50 \\
\hline 12 & $8.1(97)$ & $20 / 20(1.0)$ & 20/16 (1.2) & n.a. & 20/16 (1.2) & -0.50 & -2.25 & n.a. & n.a. \\
\hline 13 & $7.7(92)$ & 20/22 (0.9) & $20 / 20(1.0)$ & n.a. & $20 / 20(1.0)$ & -3.00 & 0.25 & -3.25 & -0.38 \\
\hline 14 & $1.6(19)$ & n.a. & n.a. & 20/25 (0.8) & 20/100 (0.2) & n.a. & n.a. & n.a. & n.a. \\
\hline 15 & $6.9(83)$ & 20/100 (0.2) & 20/133 (0.15) & $20 / 40(0.5)$ & 20/33 (0.6) & -6.00 & -10.00 & -4.25 & -9.13 \\
\hline 16 & $5.8(70)$ & $20 / 50(0.4)$ & 20/33 (0.6) & $20 / 28(0.7)$ & $20 / 20(1.0)$ & -0.50 & -0.25 & -3.75 & 0.13 \\
\hline
\end{tabular}

Max = Maximum; $F U=$ follow-up; $m=$ months; $B S C V A=$ best spectacle corrected visual acuity; $B C L V A=$ best contact lens corrected visual acuity; $D=$ diopters; $S E=$ spherical equivalent; Pre-op $=$ preoperative; $n . a .=$ not available

them, as it seems unlikely that these eyes would suddenly stabilize. A further limitation of this pilot study is the small sample size that did not allow us to analyze the clinical outcomes for different subgroups. Additional studies of larger sample size would be required to analyze the effect of manual mid-stromal dissection in different subsets of eyes.

\section{Conclusions}

In conclusion, manual mid-stromal dissection was effective in achieving stabilization of corneal ectasia in $50 \%$ of corneas with mild to moderate progressive keratoconus. As a minimally invasive and low-risk procedure, it may, in particular, be considered in keratoconic eyes ineligible for UV-CXL or ICRS in order to postpone corneal grafting, while leaving room for all other future treatment options.

\footnotetext{
Abbreviations

BCLVA: Best-contact lens corrected visual acuity; BCVA: Best corrected visual acuity; BSCVA: Best-spectacle corrected visual acuity; CCT: Central corneal thickness; D: Diopters; DALK: Deep anterior lamellar keratoplasty; ECD: Endothelial cell density; ICRS: Intrastromal corneal ring segments; KC: Keratoconus; Kmax: Maximum keratometry; PK: Penetrating keratoplasty; SD: Standard deviation; TPT: Thinnest point thickness; UV-CXL: Ultraviolet-A-induced collagen crosslinking
}

\section{Availability of data and materials}

The dataset supporting the conclusions of this article is included within the article.

\section{Authors' contributions}

Drafting of the manuscript ( $R B, K v D, G M$ ), literature search (RB, KvD), preparing Figs. (RB, GM), critical revision of the manuscript (all authors), final approval of the manuscript (all authors).

\section{Ethics approval and consent to participate}

Not applicable

Consent for publication

Not applicable

\section{Competing interests}

Dr. Melles is a consultant for DORC International/ Dutch Ophthalmic USA and SurgiCube International, Drs. Dapena and Baydoun are consultants for DORC International/Dutch Ophthalmic USA and Dr. Parker is a consultant for DORC International/ Dutch Ophthalmic USA and Ziemer Ophthalmic Systems. The remaining authors have no financial or proprietary interest in any material or method mentioned.

\section{Author details}

${ }^{1}$ Netherlands Institute for Innovative Ocular Surgery (NIIOS) Rotterdam, Laan op Zuid 88, 3071AA Rotterdam, The Netherlands. ${ }^{2}$ Melles Cornea Clinic Rotterdam, Rotterdam, The Netherlands. ${ }^{3}$ Amnitrans EyeBank Rotterdam, Rotterdam, The Netherlands. ${ }^{4}$ NIIOS-USA, San Diego, USA. ${ }^{5}$ Parker Cornea, Birmingham, AL, USA. ${ }^{6}$ Visser Contact Lens Practice Nijmegen/Rotterdam, Rotterdam, The Netherlands.

Received: 16 May 2018 Accepted: 27 September 2018

Published online: 11 October 2018

\section{References}

1. Romero-Jiménez M, Santodomingo-Rubido J, Wolffsohn JS. Keratoconus: a review. Cont Lens Anterior Eye. 2010;33:157-66.

2. Wollensak G, Spoerl E, Seiler T. Riboflavin/ultraviolet-a-induced collagen crosslinking for the treatment of keratoconus. Am J Ophthalmol. 2003: 135:620-7. 
3. Olson RJ, Pingree M, Ridges R, Lundergan ML, Alldredge C Jr, Clinch TE. Penetrating keratoplasty for keratoconus: a long-term review of results and complications. J Cataract Refract Surg. 2000;26:987-91.

4. Wagoner MD, Ba-Abbad R, King Khaled Eye Specialist Hospital Cornea Transplant Study Group. Penetrating keratoplasty for keratoconus with or without vernal keratoconjunctivitis. Cornea. 2009;28:14-8.

5. Oculus Optikgeräte GmbH. Oculus Pentacam instruction manual: measurement and evaluation system for the anterior segment of the eye. Wetzlar, Germany: Oculus Optikgeräte GmbH; 2005.

6. World Medical Association. World medical association declaration of Helsinki: ethical principles for medical research involving human subjects. JAMA. 2013; 310:2191-4.

7. Melles GR, Lander F, Rietveld FJ, Remeijer L, Beekhuis WH, Binder PS. A new surgical technique for deep stromal, anterior lamellar keratoplasty. Br J Ophthalmol. 1999:83:327-33.

8. Meiri Z, Keren S, Rosenblatt A, Sarig T, Shenhav L, Varssano D. Efficacy of corneal collagen cross-linking for the treatment of keratoconus: a systematic review and meta-analysis. Cornea. 2016;35:417-28.

9. Chan E, Snibson GR. Current status of corneal collagen cross-linking for keratoconus: a review. Clin Exp Optom. 2013;96:155-64.

10. Health Quality Ontario. Intrastromal corneal ring implants for corneal thinning disorders: an evidence-based analysis. Ont Health Technol Assess Ser. 2009;9:1-90

11. Piñero DP, Alio JL. Intracorneal ring segments in ectatic corneal disease - a review. Clin Exp Ophthalmol. 2010;38:154-67.

12. Pron G, leraci I, Kaulback K, Medical Advisory Secretariat, Health Quality Ontario. Collagen crosslinking using riboflavin and ultraviolet-A for corneal thinning disorders: an evidence-based analysis. Ont Health Technol Assess Ser. 2011;11:1-89.

13. Khan Ml, Injarie A, Muhtaseb M. Intrastromal corneal ring segments for advanced keratoconus and cases with high keratometric asymmetry. J Cataract Refract Surg. 2012;38:129-36.

14. van Dijk K, Parker J, Tong CM, Ham L, Lie JT, Groeneveld-van Beek EA, et al. Midstromal isolated Bowman layer graft for reduction of advanced keratoconus: a technique to postpone penetrating or deep anterior lamellar keratoplasty. JAMA Ophthalmol. 2014;132:495-501.

15. van Dijk K, Liarakos VS, Parker J, Ham L, Lie JT, Groeneveld-van Beek EA, et al. Bowman layer transplantation to reduce and stabilize progressive, advanced keratoconus. Ophthalmology. 2015;122:909-17.

16. Jeng BH, Farid M, Patel SV, Schwab IR. Corneal cross-linking for keratoconus: a look at the data, the food and drug administration, and the future. Ophthalmology. 2016;123:2270-2.

17. Craig JA, Mahon J, Yellowlees A, Barata T, Glanville J, Arber M, et al. Epitheliumoff photochemical corneal collagen cross-linkage using riboflavin and ultraviolet a for keratoconus and keratectasia: a systematic review and meta-analysis. Ocul Surf. 2014;12:202-14.

18. Bashour M. Risk factors for epithelial erosions in laser in situ keratomileusis. J Cataract Refract Surg. 2002;28:1780-8.

19. van Dijk K, Parker J, Baydoun L, llyas A, Dapena I, Groeneveld-van Beek EA, et al. Bowman layer transplantation: 5-year results. Graefes Arch Clin Exp Ophthalmol. 2018;256(6):1151-8.

20. Gokul A, Patel DV, Watters GA, McGhee CNJ. The natural history of corneal topographic progression of keratoconus after age 30 years in non-contact lens wearers. Br J Ophthalmol. 2017;101:839-44.

\section{Ready to submit your research? Choose BMC and benefit from:}

- fast, convenient online submission

- thorough peer review by experienced researchers in your field

- rapid publication on acceptance

- support for research data, including large and complex data types

- gold Open Access which fosters wider collaboration and increased citations

- maximum visibility for your research: over $100 \mathrm{M}$ website views per year

At $\mathrm{BMC}$, research is always in progress.

Learn more biomedcentral.com/submissions 